OPEN ACCESS

Edited by:

Quancai Sun,

Jiangsu University, China

Reviewed by:

Guoxun Chen,

The University of Tennessee, Knoxville,

United States

Qingying Zhang,

Peking University Health Science

Centre, China

*Correspondence:

Changyang Ma

macaya1024@vip.henu.edu.cn

Lijun Liu

funiuxzr2001@163.com

Wenyi Kang

kangweny@hotmail.com

tThese authors have contributed equally to this work

Specialty section

This article was submitted to Nutrition and Food Science

Technology,

a section of the journa

Frontiers in Nutrition

Received: 01 December 2021 Accepted: 27 December 2021

Published: 20 January 2022

Citation:

Tang Q, Chen S, Rizvi SAH, Qu J, Wang L, Wang S, Ma C, Liu L and Kang W (2022) Two Alkaloids From Delphinium brunonianum Royle, Their Anti-inflammatory and Anti-oxidative

Stress Activity via NF- $\kappa B$ Signaling Pathway. Front. Nutr. 8:826957. doi: 10.3389/fnut.2021.826957

\section{Two Alkaloids From Delphinium brunonianum Royle, Their Anti-inflammatory and Anti-oxidative Stress Activity via NF-кB Signaling Pathway}

\author{
Qi Tang ${ }^{1 \dagger}$, Sitan Chen ${ }^{1 \dagger}$, Syed Arif Hussain Rizvi ${ }^{2 \dagger}$, Jiaojiao Qu ${ }^{1,3}$, Li Wang ${ }^{1,3}$, \\ Senye Wang ${ }^{1,3}$, Changyang Ma ${ }^{1,3,4 *}$, Lijun Liu ${ }^{1,5 *}$ and Wenyi Kang ${ }^{1,3,4 *}$
}

\begin{abstract}
${ }^{1}$ National R\&D Center for Edible Fungus Processing Technology, Henan University, Kaifeng, China, ${ }^{2}$ Pakistan Agricultural Research Council, Islamabad, Pakistan, ${ }^{3}$ Functional Food Engineering Technology Research Center, Kaifeng, China, ${ }^{4}$ Joint International Research Laboratory of Food and Medicine Resource Function, Kaifeng, China, ${ }^{5}$ Huaihe Hospital, Henan University, Kaifeng, China
\end{abstract}

In this study, we isolated and identified four compounds in Delphinium brunonianum Royle, and they were Delbrunine (1), 4-O- $\alpha$-D-Glucosyl benzoic acid (2), Kaempferol 3-O- $\beta$-D-glucopyranoside 7-O- $\alpha$-L-rhamnopyranoside (3) and Eldeline (4). Furthermore, the anti-inflammatory activity of these compounds was screened in RAW264.7 cells. The results showed that the anti-inflammatory activities of compounds $\mathbf{2}$ and $\mathbf{3}$ were weak, and $\mathbf{1}, \mathbf{4}$ had good anti-inflammatory activity. The macrophage inflammation model was established by lipopolysaccharide (LPS). Then, the anti-inflammatory activity was evaluated by ELISA kits, qRT-PCR experiment and western blot experiment. And the anti-oxidative stress activity was assessed by flow cytometry. The results showed that compounds $\mathbf{1}, \mathbf{4}$ could significantly inhibit the elevation of inflammatory factors nitric oxide (NO), tumor necrosis factor- $\alpha$ (TNF- $\alpha$ ), interleukin-6 (IL-6), and also had obvious inhibitory effects on the production of inducible nitric oxide synthase (iNOS) and cyclooxygenase 2 (COX-2). In addition, compounds $\mathbf{1}$ and $\mathbf{4}$ could effectively inhibit the overexpression of reactive oxygen species (ROS) in RAW264.7 cells that activated by LPS. These results indicated that compounds $\mathbf{1}$ and $\mathbf{4}$ may exert anti-inflammatory and anti-oxidative stress effects through the NF- $\kappa$ B signaling pathway.

Keywords: Delphinium brunonianum Royle, anti-inflammatory, RAW264.7 cells, LPS, Delbrunine, Eldeline

\section{INTRODUCTION}

Inflammation is the basis of many pathological processes (1). The main symptoms associated with inflammatory disorders include body pain, arthralgia, myalgia, fever, local swelling and frequent infections (2). Infection and tissue damage are the main causes of inflammation, they recruit leukocytes and hemoglobin to transfer to the affected tissues (3). The metabolic diseases can also induce chronic inflammation in the body, such as insulin resistance, type 2 diabetes, coronary artery disease and fatty liver disease (4-6). During inflammation, several types of immune cells 


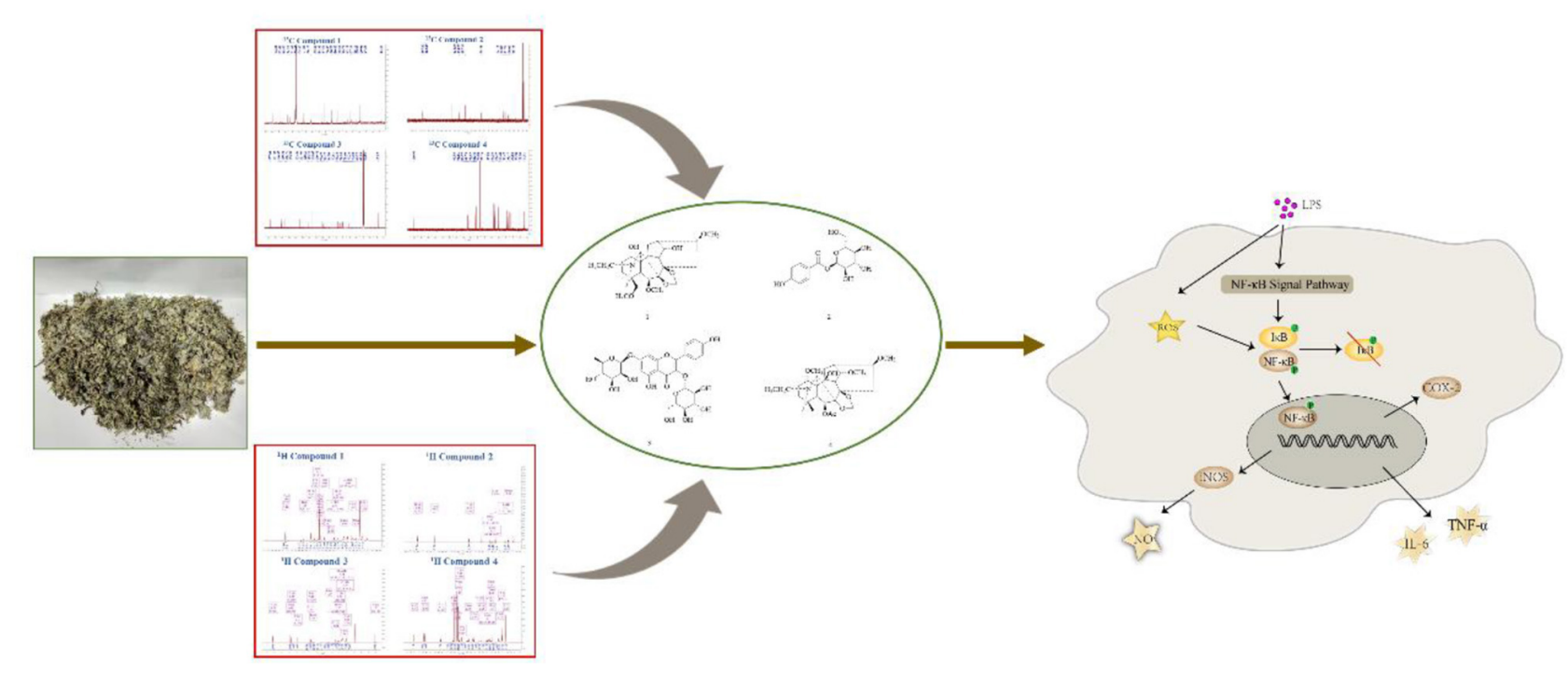

GRAPHICAL ABSTRACT | Two alkaloids with anti-inflammatory from D. brunonianum via NF-kB signaling pathway.

are activated, including macrophages, which have been found to play a central role in the anti-inflammatory process (7). The two basic functions of macrophages are phagocytosis and adaptive immune response $(8,9)$. Phagocytosis plays a vital in the body's response to acute inflammation, it can quickly resist the invasion of foreign pathogens. In addition, in chronic inflammation, it is also particularly important to remove apoptotic cells. And macrophages can present antigens together with dendritic cells (9-11). At the same time, macrophages can also secrete a variety of powerful catalytic factors, such as tumor necrosis factors and interleukins (12). Excessive release of inflammatory mediators can cause damage to the body, so inhibiting the production of these cytokines may be an effective strategy for the treatment of inflammatory diseases. NO is produced by L-arginine under the action of nitric oxide synthase. The expression of iNOS increases under inflammation and immune stimulation, thereby promoting the production of NO (13). Excessive NO could promote the occurrence and development of inflammatory diseases. In addition, TNF- $\alpha$ and IL- 6 are the main cytokines that mediate inflammation. TNF- $\alpha$ is mainly produced by macrophages which can activate white blood cells and endothelial cells, causing extensive damage to tissues. IL-6 is the most important inflammatory mediator involved in inducing the acute phase protein response during fever (14).

Although many synthetic anti-inflammatory drugs such as steroids, non-steroidal anti-inflammatory drugs and immunosuppressants have been widely used in inflammatory diseases, their long-term use is limited by related side effects $(15,16)$. Therefore, many plants are used to explore safe, effective and easily available anti-inflammatory drugs (17). Many studies have shown that medicinal plants can be used to treat inflammation and have been successfully converted into convenient and effective dosage forms for modern medicine (18). D. brunonianum, belonging to Delphinium genus (Ranunculaceae family), usually has the effects of clearing heat, detoxifying, anti-inflammatory and analgesic as folk medicine. The past research showed that the alkaloids are the main constituents, and flavonoids and sterols were also found, with the effects of antibacterial, antiepileptic, detoxification, and Alzheimer's disease treatment. For example, hydroalcoholic extract and fractions obtained from D. brunonianum presented significant diuretic and natriuretic effects when given to rats through the oral route (19). Also, past research has shown that the anti-tumor activity of $D$. brunonianum, but its anti-inflammatory active ingredients and mechanism are still unclear (20). In this research, four compounds were isolated from D. brunonianum, identified as Delbrunine $(21,22), 4-O-\alpha-\mathrm{D}$-Glucosyl benzoic acid $(23,24)$, Kaempferol 3-O- $\beta$-D-glucopyranoside 7-O- $\alpha-L$ rhamnopyranoside (25) and Eldeline (26) by comparing with the published data (Figure 1). The purity of all compounds was more than 95\%. Studies have shown that LPS can stimulate macrophages to induce inflammation and increase the production of reactive oxygen species (27). Therefore, this study established macrophage inflammation model using LPS to explore the anti-inflammatory activity and mechanism of D. brunonianum.

\section{MATERIALS AND METHODS}

\section{Reagents and Instruments}

The following reagents were used in this research: RAW264.7 cells were purchased from the Typical Culture Preservation Committee Cell Bank, Chinese Academy of Sciences. DMEM (Solarbio, Beijing, China). FBS (Gibco, GrandIsland, USA). Penicillin-streptomycin mixture, Nucleoprotein extraction kit, BCA protein quantitative kit and protease phosphatase inhibitor 
(SolarBio, Beijing, China). LPS (Sigma-Aldrich, St. Louis, MO, USA). NO kit and ROS kit (Beyotime Biotechnology Shanghai, China). Mouse TNF- $\alpha$ Enzyme-linked immunosorbent assay (ELISA) kit and mouse IL-6 ELISA kit (4A Biotech Co, Ltd. Beijing, China). Evo M-MLV RT Kit with gDNA Clean and SYBG Green Premix Pro Taq HS qPCR kit (Tli RNadeH Plus, Accurate Biotechnology, Hunan, China). Antibody iNOS, COX-2, NF-кB P65, p-NF-кB P65 (Cell Signaling, USA). Primers were designed and synthesized by Thermo Fisher Scientific (Shanghai, China). The primers were shown in Supplementary Table 1.

\section{Extraction and Isolation}

The dried aerial parts of $D$. brunonianum were extracted with petroleum ether 3 times, and the filter residue was extracted with $70 \%$ ethanol 3 times (each time for 7 days). By concentrating the combined extract under reduced pressure, $470 \mathrm{~g}$ of the extract was obtained. The extract was eluted by D101 macroporous resin with six solvents, which were water, $20 \%$ ethanol, $40 \%$ ethanol, $60 \%$ ethanol, $80 \%$ ethanol and $95 \%$ ethanol. Six components were obtained (Fr. A-Fr. F). Forty percent components (Fr. B $60 \mathrm{~g}$ ) were separated by silica gel column chromatography,

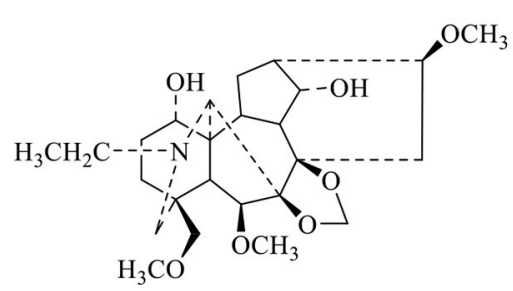

1<smiles>C[C@@H]1O[C@H](Oc2cc(O)c3c(=O)c(O[C@@H]4O[C@H](CO)[C@@H](O)[C@H](O)[C@H]4O)c(-c4ccc(O)cc4)oc3c2)[C@H](O)[C@H](O)[C@H]1O</smiles>

3<smiles>O=C(O[C@@H]1O[C@H](CO)[C@@H](O)[C@H](O)[C@H]1O)c1ccc(O)cc1</smiles>

2

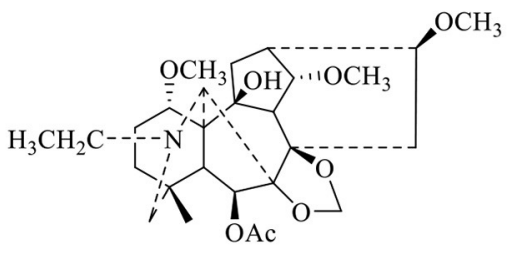

4

FIGURE 1 | Structures of compounds 1-4 from D. brunonianum

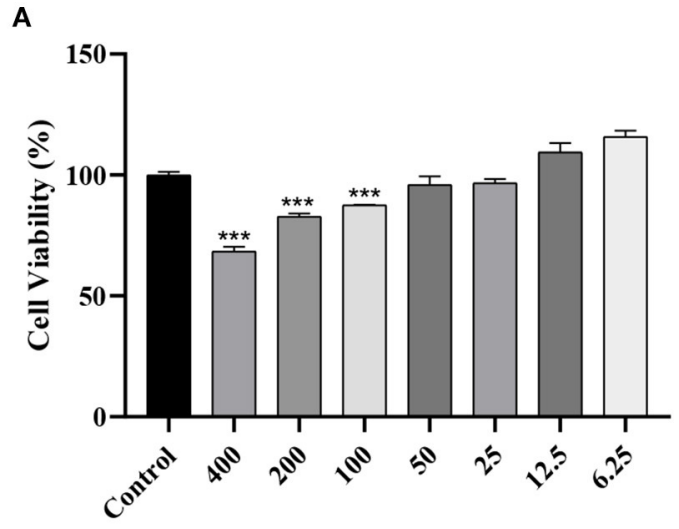

Compound $1(\mu \mathrm{M})$

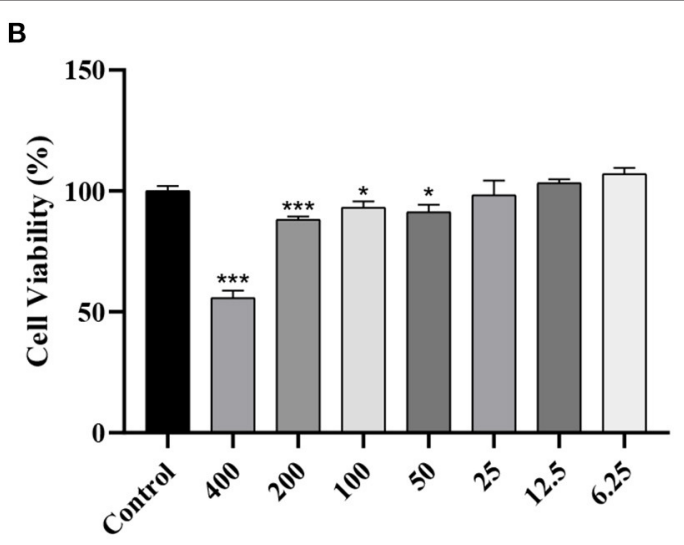

Compound $4(\mu \mathrm{M})$

FIGURE 2 | Effects of compound $\mathbf{1}$ (A), compound $\mathbf{4}$ (B) on the viability of RAW264.7 cells. The data were expressed as mean \pm standard deviation, $n=6$. ${ }^{\star \star \star} P<$ $0.001,{ }^{*} P<0.05$ compared with the control group. 
and 10 fractions fr.1-10 were obtained by gradient elution with $\mathrm{CHCl}_{3}-\mathrm{MeOH}$ (40:1-1:1).

Fr.1 was eluted by Sephadex LH-20 with methanol, then eluted with $\mathrm{CHCl}_{3}-\mathrm{MeOH}$ (40:1-1:1) gradient by silica gel column chromatography. Fr.1-3 was eluted with $\mathrm{CH}_{2} \mathrm{Cl}_{2}$ $\mathrm{MeOH}$ (50:1-1:1, v/v) gradient through reduced pressure silica gel column chromatography to obtain compound 1 (40 mg). Fr.5 was eluted with EtOAc-MeOH (40:1-1:1, v/v) gradient by silica gel column chromatography, and then compound 2 was obtained by semi-prep. HPLC $\left(\mathrm{MeOH}-\mathrm{H}_{2} \mathrm{O}, 50: 50, \mathrm{v} / \mathrm{v}\right)$. Compound 3 (500 mg) was obtained from Fr.8 by repeated recrystallization of $\mathrm{CH}_{2} \mathrm{Cl}_{2}-\mathrm{MeOH}$. Fr. 2-2 was separated by silica gel column chromatography, eluted with Petrol-Acetone $(6: 1, \mathrm{v} / \mathrm{v})$ gradient, recrystallized with petroleum ether to obtain fr.2-2, and then compound 4 (30 $\mathrm{mg}$ ) were obtained by silica column chromatography.

\section{Cell Culture}

The RAW264.7 cells were cultured in an incubator at $37^{\circ} \mathrm{C}$ and $5 \% \quad \mathrm{CO}_{2}$ and maintained in DMEM medium with high glucose containing $10 \%$ FBS and $1 \%$ double antibiotics (Penicillin and Streptomycin). The cell fusion rate reached about $80 \%$, and the ratio of extended is $1: 3$. The cells of the logarithmic growth phase were chosen for the following assays.

\section{Cell Viability Assay}

The effects of compounds 1, 4 on the viability and cytotoxicity of RAW264.7 cells were determined by MTT assay. The method was the same as Wang's experiment (28).

\section{NO Production Assays}

The Griess reaction was applied to determine the NO level secreted by RAW264.7 cells. The cells were treated in a 24well plate at $1.6 \times 10^{5}$ cells/well for $24 \mathrm{~h}$. Then model group and the experimental group were, respectively, treated with LPS $(1 \mu \mathrm{g} / \mathrm{mL}), \mathrm{LPS}(1 \mu \mathrm{g} / \mathrm{mL})+$ compounds $1(50,25,12.5 \mu \mathrm{M})$, or LPS $(1 \mu \mathrm{g} / \mathrm{mL})+$ compounds $4(25,12.5,6.25 \mu \mathrm{M})$ for $24 \mathrm{~h}$, while the control group was treated only with the DMEM medium. After that, the culture supernatant of RAW264.7 cells was collected to test the secretion of nitric oxide according to the Griess reagent kit.

\section{A}

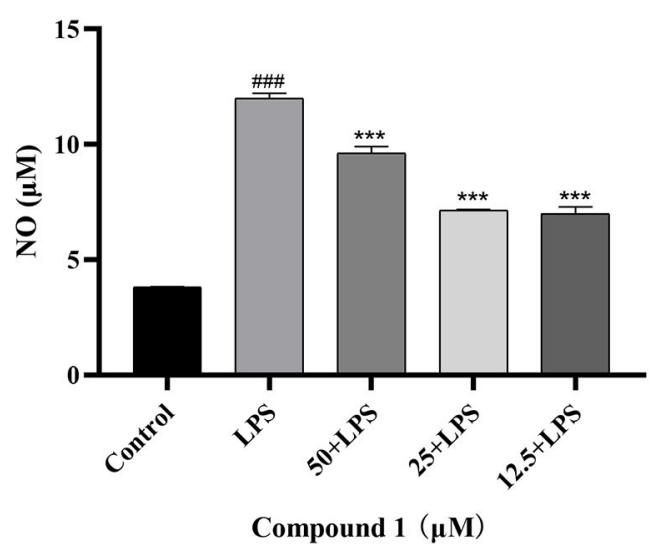

C

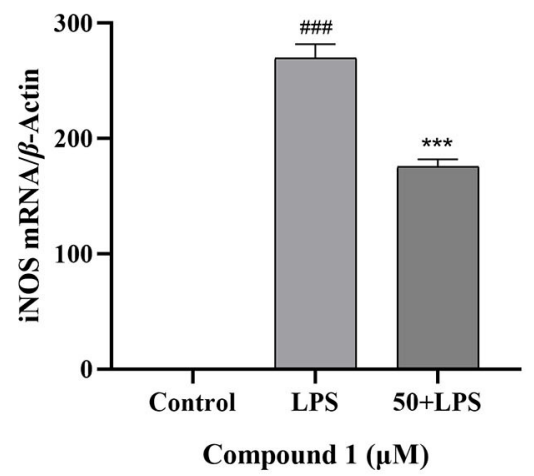

B

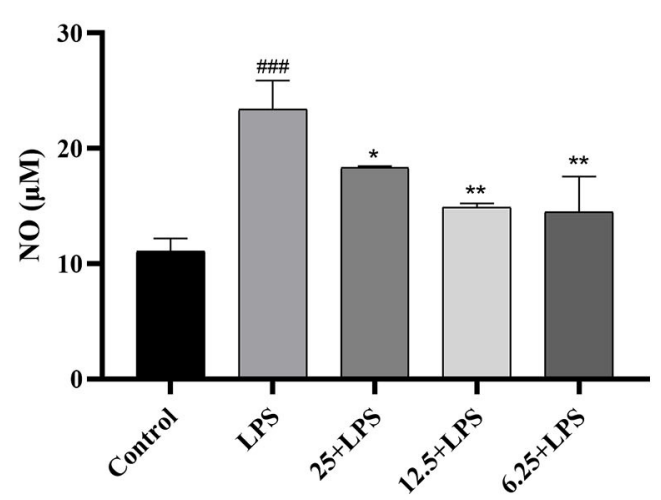

Compound $4(\mu \mathrm{M})$

D

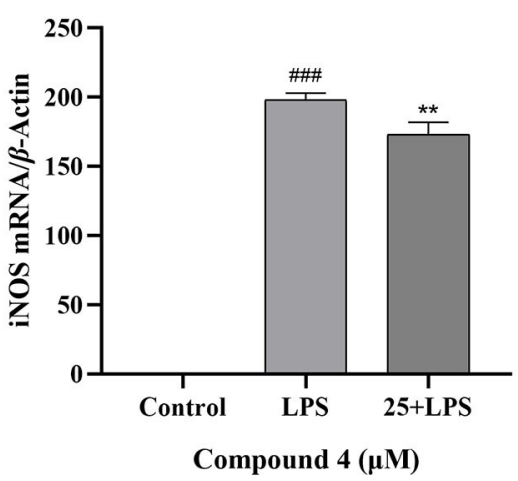

FIGURE 3 | Effects of compound $\mathbf{1}$ (A), compound $\mathbf{4}$ (B) on NO production and effects of compound $\mathbf{1}$ (C), compound $\mathbf{4}$ (D) on iNOS mRNA expression in RAW264.7 cells. The data were expressed as mean \pm standard deviation, $n=3$. Compared with the control, \#\#\#P<0.001. Compared with the LPS group, ${ }^{\star \star \star} P<$ $0.001,{ }^{\star *} P<0.01,{ }^{*} P<0.05$. 


\section{Measurement of TNF- $\alpha$ and IL-6}

RAW264.7 cells were treated according to the above method, and the levels of TNF- $\alpha$ and IL- 6 was determined by ELISA kits according to the manufacturer's instructions.

\section{ROS Level}

The content of ROS in RAW264.7 cells was carried by the fluorescent probe DCFH-DA following the kit instructions. The ROS levels was measured using Flow Cytometry.

\section{Western Blot Analysis}

Total protein was obtained after lysing the cells (RIPA lysate). The protein content was determined by BCA protein assay kit. The western blot method was the same as the experiment done by Wang et al. (28).

\section{Quantitative Real-Time Polymerase Chain Reaction}

The process of cell culture and treatment was similar to the above method. Total RNA was isolated from the RAW264.7 cells via Trizol reagent. The method of qRT-PCR was referred to Zang's experiment (29).

\section{Statistical Analysis}

All the experimental data were expressed as mean \pm SD. SPSS 19.0 software was used for data statistical analysis. Statistical significance was calculated by the one-way ANOVA analysis. $P$ $<0.05$ were considered statistically significant.

\section{RESULT}

\section{Effects of Compounds 1 and 4 on RAW264.7 Cells Viability}

To explore the effects of compounds 1 and 4 on RAW264.7 cells viability, we used MTT assay to test the effects of compound 1 and compound 4 at the dose range of 6.25-400 $\mu \mathrm{M}$. In Figure 2, compound 1 and compound 4 displayed obvious cytotoxic effects on RAW264.7 cells. Therefore, 50, 25, $12.5 \mu \mathrm{M}$ of compound 1 and $25,12.5,6.25 \mu \mathrm{M}$ of compound 4 were chosen for the further experiments.

\section{Effects of Compound 1 and Compound 4 on NO Secretion and mRNA Expression of iNOS in RAW264.7 Cells}

$\mathrm{NO}$ is an important inflammatory mediator that played a pivotal role in cell survival and death (30). In Figure 3, the concentration
A

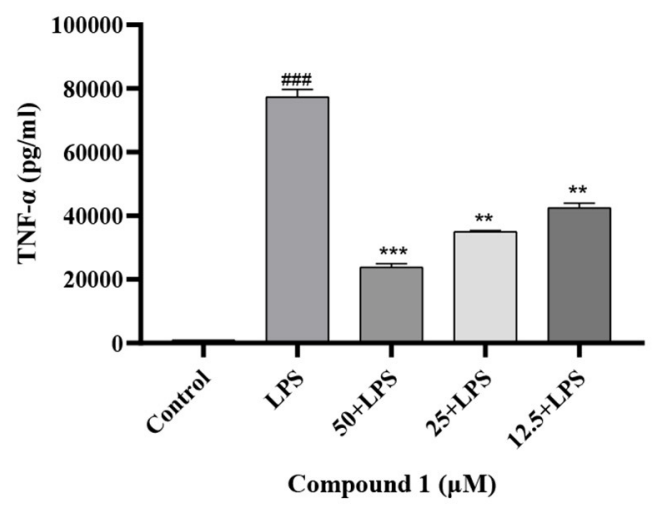

C

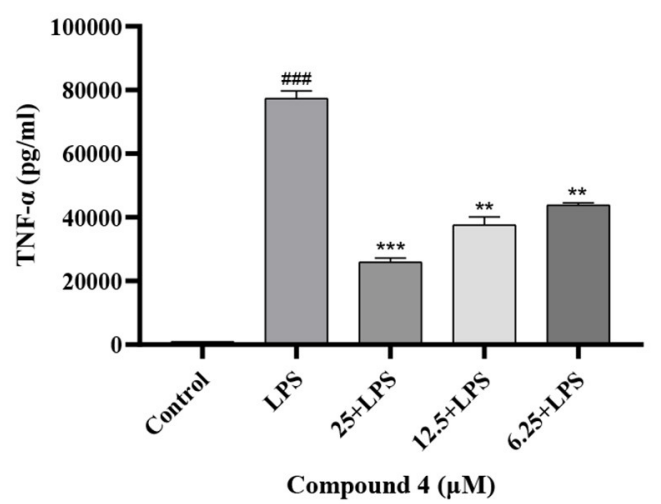

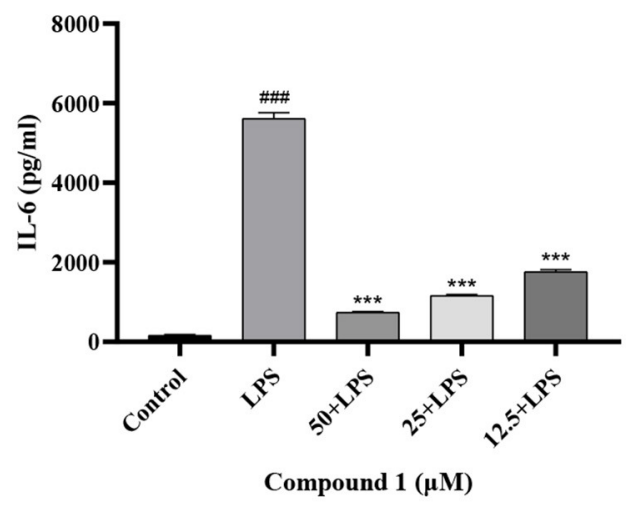

D

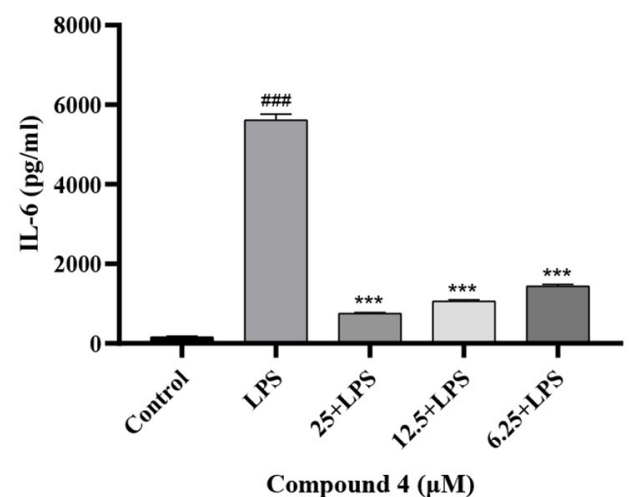

FIGURE 4 | Effects of compound $\mathbf{1}(\mathbf{A}, \mathbf{B})$ and compound $\mathbf{4}$ (C,D) on the secretion of TNF- $\alpha$, IL-6 in LPS-Induced RAW264.7 Cells. The data were expressed as mean

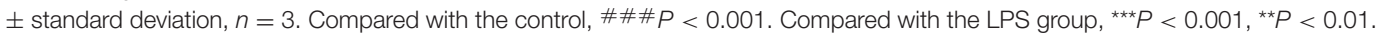


of NO was increased obviously, when RAW264.7 cells were stimulated by LPS. Compound $\mathbf{1}$ and compound $\mathbf{4}$ could reduce NO production caused by LPS conspicuously. Under normal physiological conditions, the iNOS activity of cells is almost not expressed. When RAW264.7 cells were induced by LPS, the expression of iNOS in cells increased, resulting in the secretion of NO increased (31). To further verify the way that compound 1 and compound 4 regulated the release of NO, the expression level of iNOS mRNA was detected. The results showed that compound $\mathbf{1}$ and compound $\mathbf{4}$ could markedly reduce the expression level of iNOS mRNA in RAW264.7 cells (Figures 3C,D).

\section{Effects of Compound 1 and Compound 4 on the Secretion of TNF- $\alpha$, IL-6 in \\ LPS-Induced RAW264.7 Cells}

TNF- $\alpha$ and IL- 6 are mainly produced by macrophages as cytokines with multiple functions $(32,33)$. In Figure 4, the secretion of TNF- $\alpha$, IL- 6 increased considerably after LPS induction as compared with the control group. Compound $\mathbf{1}$ and compound 4 both significantly reduced the secretion of TNF- $\alpha$, IL-6 in a dose dependent manner. Furthermore, the mRNA levels of cytokines were measured by qRT-PCR. As shown in Figure 5, compound $1(50 \mu \mathrm{M})$, compound $4(25 \mu \mathrm{M})$ were found to contribute to a considerable reduction of the increased mRNA expression of TNF- $\alpha$, IL-6 in the RAW264.7 cells stimulated by LPS.

\section{Effects of Compound 1 and Compound 4 on LPS-Induced Protein Expression of iNOS and COX-2}

The protein expressions of iNOS and COX-2 were determined to evaluate the effect of compound 1 and compound 4 on proinflammatory mediators. In Figure 6, LPS can significantly increase the expression of iNOS and COX-2 compared with the control group. Meanwhile, the excessive expression of iNOS and COX-2 was inhibited significantly by compound $\mathbf{1}$ and compound 4 compared with the LPS group.

\section{Effect of Compound 1 and Compound 4 on LPS-Induced Oxidative Stress}

Excessive reactive oxygen species is the major cause of high mortality caused by local inflammation and sepsis (34). In this study, the RAW264.7 cells were stimulated by LPS to release a large number of endogenous ROS, which can mediate the transmission of inflammatory signals in macrophages. In
A

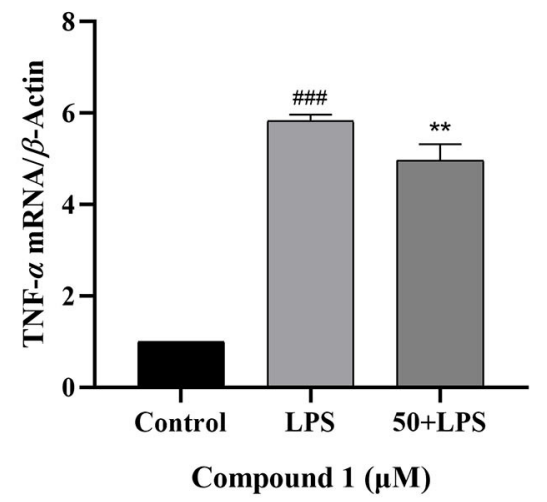

C

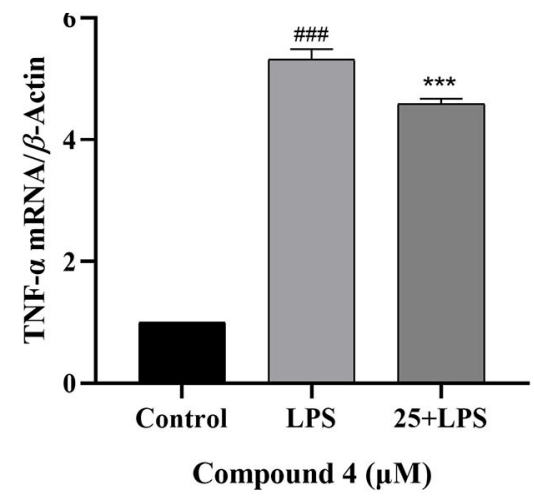

B

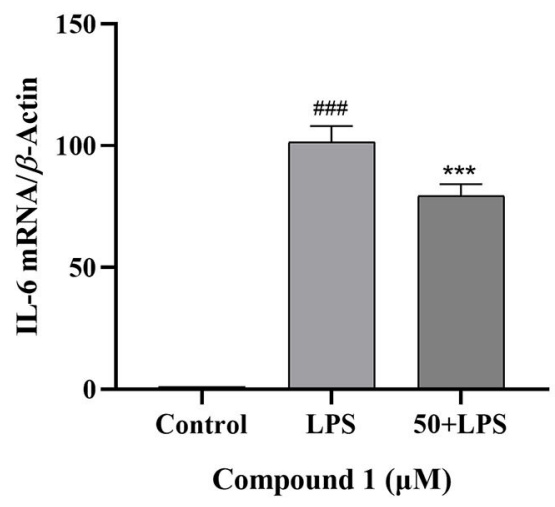

D

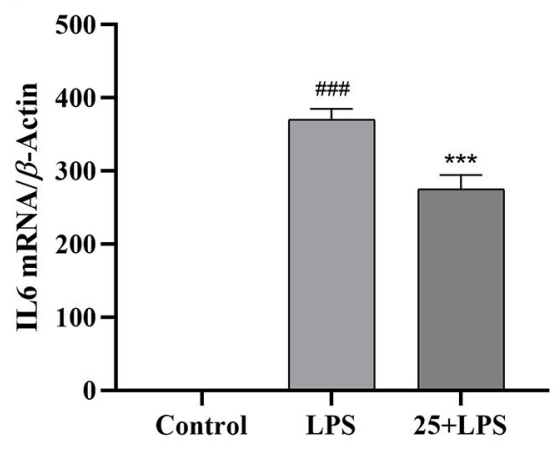

Compound $4(\mu \mathrm{M})$

FIGURE 5 | Effects of compound $\mathbf{1}$ (A,B) and compound $\mathbf{4}$ (C,D) on the expression of TNF- $\alpha$, IL-6 mRNA in LPS-Induced RAW264.7 cells. The data were expressed as mean \pm standard deviation, $n=3$. Compared with the control, $\# \# \# P<0.001$. Compared with the LPS group, ${ }^{\star \star \star} P<0.001,{ }^{\star \star} P<0.01$. 
Figure 7, the peak shape of cell fluorescence in the LPS group shifted significantly to the right compared with the control group, which illustrated the intracellular ROS increase sharply. Compound 1 at 50 or $25 \mu \mathrm{M}$ could effectively inhibit the overexpression of ROS in RAW264.7 cells induced by LPS, while compound 1 at $12.5 \mu \mathrm{M}$ had little inhibitory effect on it. At the same time, compound 4 at $25,12.5$, and $6.25 \mu \mathrm{M}$ could markedly inhibit the overexpression of ROS.

\section{Effects of Compound 1 and Compound 4 on NF-кB Signaling Pathway in RAW264.7 Cells Induced by LPS}

When the body has an inflammatory response, multiple signal pathways are activated and coordinated to jointly regulate the expression of pro-inflammatory and anti-inflammatory factors in innate and adaptive immune cells, tissues, or recruited from the blood (35). In Figure 8, compound $\mathbf{1}$ and compound $\mathbf{4}$ displayed a significant suppression on the expression of proteins p-p65 in the NF- $\kappa$ B signaling pathways of LPS-induced RAW264.7 cells.

\section{DISCUSSION}

Due to the complexity of different inflammation, developing highly effective and low-toxic drugs is still a challenge for pharmaceutical chemists (36). Alkaloids widely exist in plants and have a variety of anti-inflammatory activities. They can be used as lead compounds or candidate drugs to help us design and find new anti-inflammatory drugs (37). Alkaloids in many natural products are used in the treatment of inflammation. Delavatine A is a special isoquinoline alkaloid isolated from Incarvillea delavayi. It was found that it can significantly inhibit the production of proinflammatory mediators (38). A novel steroidal alkaloid, Solanine A, is isolated from Solanum nigrum Linn, exhibits significant inhibition of NF- $\kappa \mathrm{B}, \mathrm{ERK} 1 / 2$, Akt and STAT1 signaling pathways to exert anti-inflammatory activity in macrophages that induced by $\mathrm{LPS} / \mathrm{IFN} \gamma$ (39). Isoquinoline alkaloid glycoside isolated from Phellodendron chinense Schneid can inhibit the excessive production of inflammatory mediators and show good antiinflammatory activity (40). Therefore, exploring alkaloids with therapeutic potential from natural resources is a rich

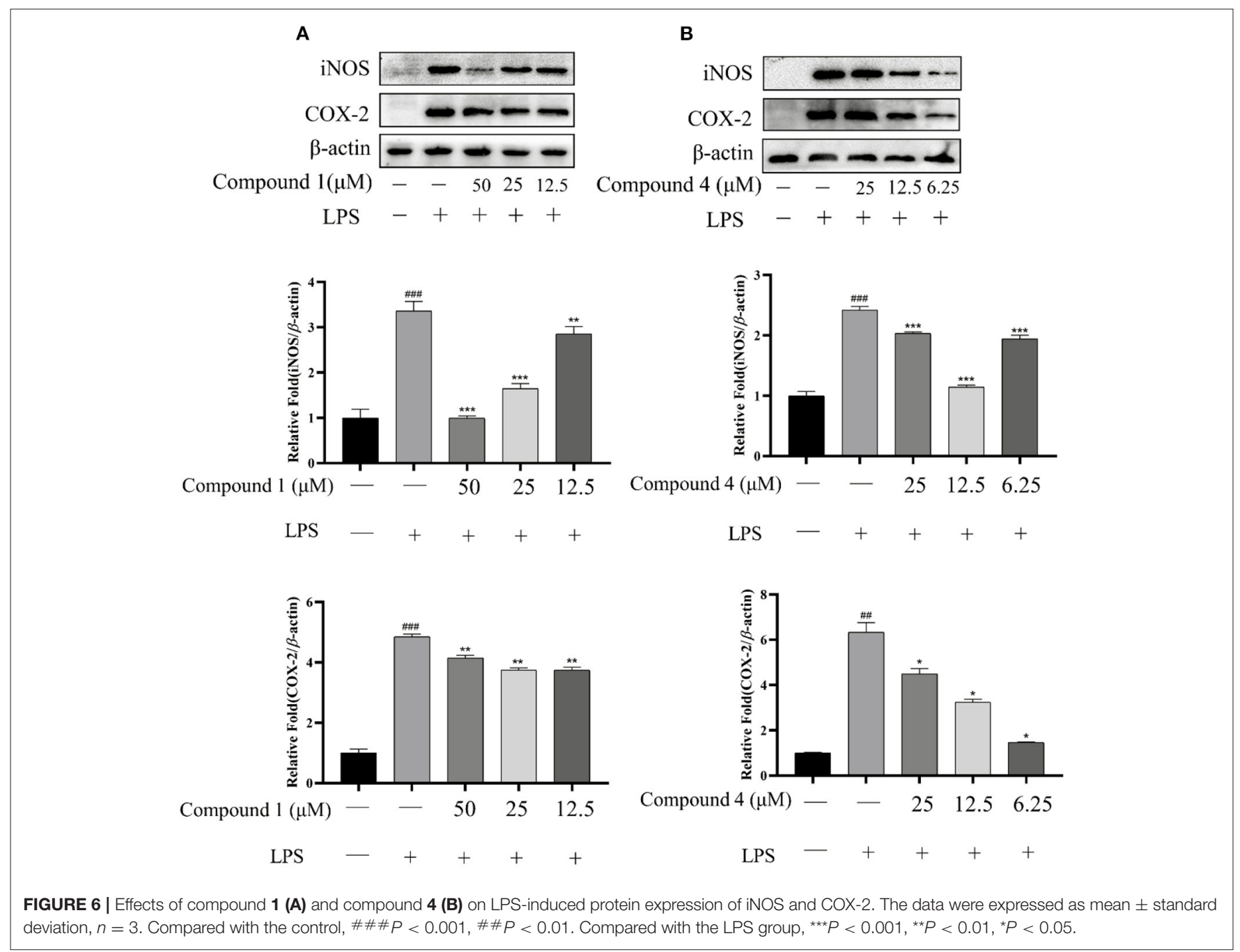




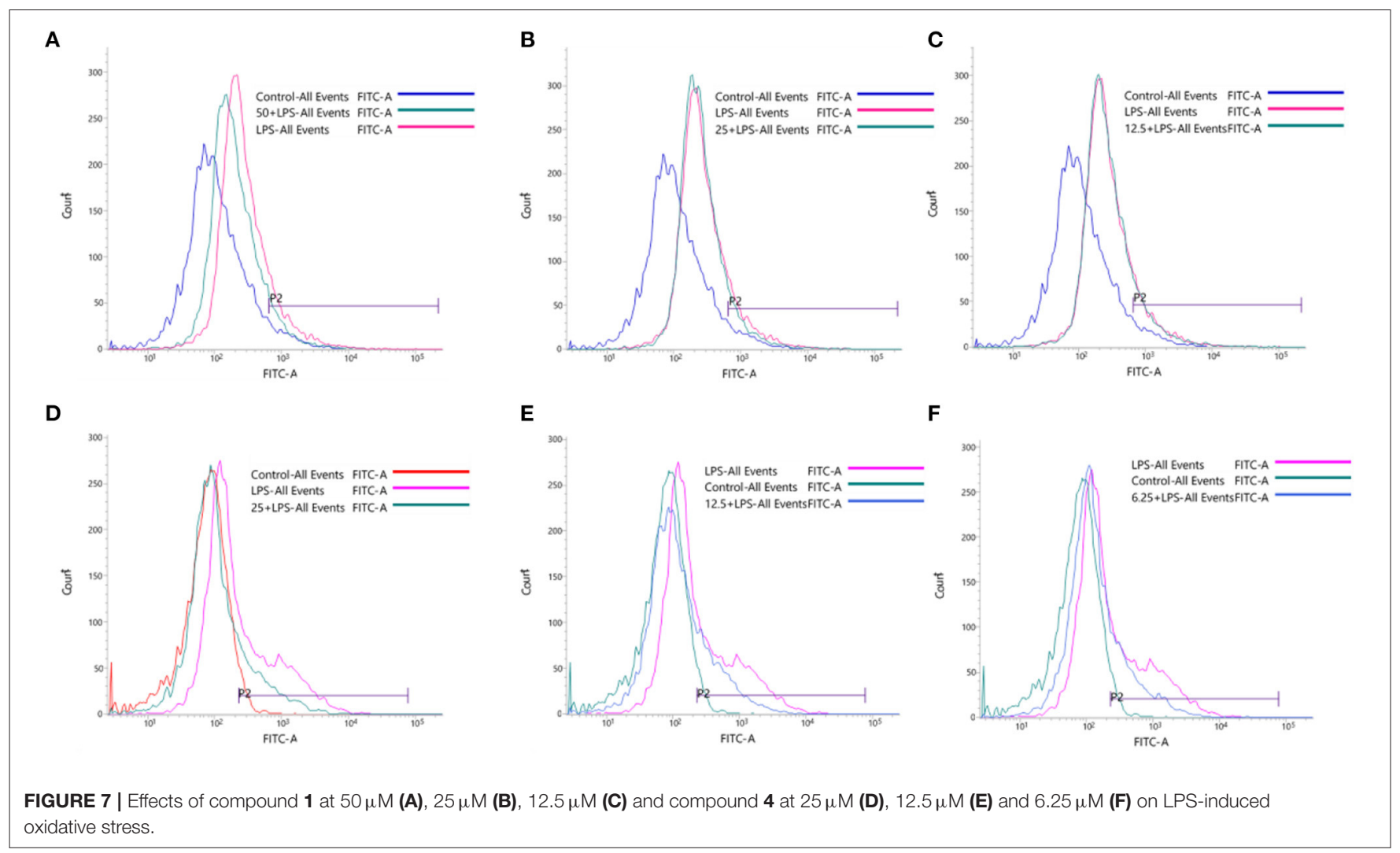

oxidative stress.

A

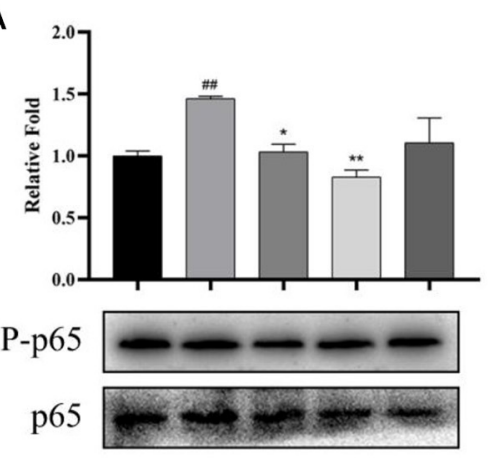

B

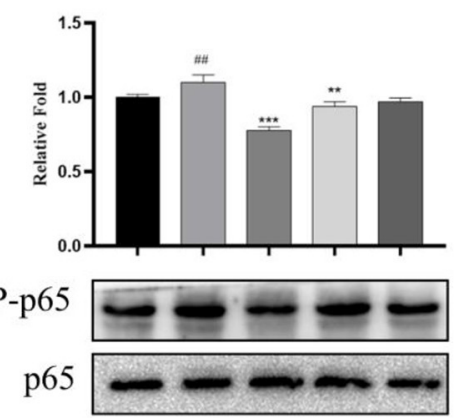

$$
\begin{array}{rlllllllllll}
\text { Compound } 1(\mu \mathrm{M}) & - & - & 50 & 25 & 12.5 & \text { Compound } 4(\mu \mathrm{M}) & - & - & 25 & 12.5 & 6.25 \\
\text { LPS } & - & + & + & + & + & \text { LPS } & - & + & + & + & +
\end{array}
$$

FIGURE 8 | Effects of compound $\mathbf{1}$ (A) and compound $\mathbf{4}$ (B) on NF- $\kappa$ B signaling pathway. The data were expressed as mean \pm standard deviation, $n=3$. Compared with the control, ${ }^{\# \# P}<0.01$. Compared with the LPS group, ${ }^{* \star *} P<0.001,{ }^{\star \star} P<0.01,{ }^{*} P<0.05$.

source for discovering and developing new compounds with medical value.

D. brunonianum is a folk medicine plant with multiple biological properties, including anti-inflammatory, anti-tumor, anti-viral and anti-oxidation. However, its anti-inflammatory active ingredients and mechanism are unclear that needed to be explored. Studies have shown excessive NO is the most typical biomarker of inflammation (41). And inflammatory cytokines are produced by a variety of cells, the most important of which are macrophages (42). They can play a variety of functions in the process of the inflammatory response, such as activating endothelium and leukocytes and inducing acute phase reactions (43). In this study, we detected the anti-inflammatory activity of four compounds that isolated and identified from D. brunonianum. It was found that the alkaloid, compound $\mathbf{1}$ and compound 4 could significantly reduce the production of pro-inflammatory factors NO, TNF- $\alpha$, IL- 6 caused by LPS, at the same time, this result was verified by PCR at mRNA level. 
These results indicate that compound $\mathbf{1}$ and compound $\mathbf{4}$ have significant anti-inflammatory activity.

iNOS and COX-2 are two important proteins in the initiation and progression of the inflammatory process, and play key roles in the synthesis of NO and PGE2, respectively $(44,45)$. As an inflammatory mediator, prostaglandin participates in the pathological process of inflammation, cancer, and a variety of cardiovascular diseases (46). In addition, prostaglandin binds to specific receptors to mediate a series of cell activities such as cell proliferation, differentiation, and apoptosis (47). COX is a key enzyme in the process of prostaglandin synthesis (48). Therefore, the expression of iNOS and COX-2 is also overproduction in RAW264.7 cells induced by LPS will be significantly upregulated. In our studies, the western blot results showed that the excessive expression of iNOS and COX-2 was inhibited significantly by compound $\mathbf{1}$ and compound $\mathbf{4}$ compared with the LPS group. This result further shows that compound $\mathbf{1}$ and compound $\mathbf{4}$ have anti-inflammatory activity.

Oxidative stress response refers to a state in which the body's highly active molecules such as active oxygen are excessively produced when the body is subjected to various harmful stimuli, and the oxidation and antioxidant effects in the body are out of balance (49). ROS is generally considered to be a harmful inflammatory mediator (50). The production of ROS can promote the release of various inflammatory factors. On the contrary, the increase in the secretion of inflammatory mediators promotes the production of ROS and aggravates the oxidative stress damage of cells (51). In this study, we detected the content of ROS in RAW264.7 stimulated by LPS using Flow Cytometry, the LPS group released a large number of endogenous ROS, and compound $\mathbf{1}$ and compound $\mathbf{4}$ could effectively inhibit the overexpression of ROS in LPS-induced RAW264.7 cells, although the effect of the low-dose group of compound $\mathbf{1}$ is not obvious. Our results further suggest that compound $\mathbf{1}$ and compound $\mathbf{4}$ not only have anti-inflammatory activity but also can effectively inhibit the overexpression of ROS.

To further explore the anti-inflammatory mechanism of compound $\mathbf{1}$ and compound $\mathbf{4}$, we detected the expression of key proteins in the NF- $\kappa \mathrm{B}$ signaling pathway through western blot experiments. It is well-known that the production of inflammatory cytokines and oxidative stress are related to the activation of NF- $\kappa \mathrm{B}$ (35). The NF- $\kappa \mathrm{B}$ transcription factor family controls the expression of important regulatory genes in the processes of immunity, inflammation, death and cell proliferation, and is very important as a stressor in the cellular environment (52). In our studies, we detected the expression of key proteins p-p65 and p65, western blot results showed that compound $\mathbf{1}$ and compound $\mathbf{4}$ displayed a significant suppression on the expression of key proteins p-p65 in the NF- $\kappa$ B signaling pathways. Thus, we preliminarily speculated that compound $\mathbf{1}$

\section{REFERENCES}

1. Medzhitov R. Origin and physiological roles of inflammation. Nature. (2008) 454:428-35. doi: 10.1038/nature07201 and compound 4 exerted the greatest inhibition toward LPSinduced oxidative stress and inflammatory response via the NF- $\kappa \mathrm{B}$ signaling pathway. However, how compound 1 and compound 4 regulate the expression of PP65 and activate the NF- $\kappa \mathrm{B}$ signaling pathway is still unknown. In the process of inflammation, several different signal pathways may be activated and coordinated with each other to regulate the expression of pro-inflammatory mediators and anti-inflammatory mediators. Therefore, whether compound $\mathbf{1}$ and compound $\mathbf{4}$ exert their anti-inflammatory effects through other pathways is also a question worth considering.

\section{CONCLUSIONS}

In conclusion, we proved that the alkaloid, extracted and separated from Delphinium brunonianum Royle, could reduce the production of pro-inflammatory mediators in LPS-induced RAW264.7 cells, and this effect of compound $\mathbf{1}$ and compound 4 is involved in the NF- $\kappa$ B signaling pathway. In addition, they can effectively inhibit the overexpression of ROS. Therefore, compound $\mathbf{1}$ and compound $\mathbf{4}$ may be promising drugs for the treatment of inflammatory diseases.

\section{DATA AVAILABILITY STATEMENT}

The original contributions presented in the study are included in the article/Supplementary Material, further inquiries can be directed to the corresponding author/s.

\section{AUTHOR CONTRIBUTIONS}

QT and SC performed experiments and writing original draft preparation. SR and SW analyzed and summarized data. JQ and LW contributed to the data acquisition. CM and LL supervised project administration. WK provided resources, funding, and reviewed the manuscript. All authors read and approved the final paper.

\section{FUNDING}

This work was funded by Research on Precision Nutrition and Health Food, Department of Science and Technology of Henan Province (CXJD2021006).

\section{SUPPLEMENTARY MATERIAL}

The Supplementary Material for this article can be found online at: https://www.frontiersin.org/articles/10.3389/fnut.2021. 826957/full\#supplementary-material 
3. Matsuo H, Yoshimura Y, Fujita S, Maeno Y, Tanaka S. Role of systemic inflammation in functional recovery, dysphagia, and 1-year mortality in heart failure: a prospective cohort study. Nutrition. (2021) 91:111465. doi: 10.1016/j.nut.2021.111465

4. Chawla A, Nguyen KD, Goh Y. Macrophage-mediated inflammation in metabolic disease. Nat Rev Immunol. (2011) 11:738-49. doi: 10.1038/nri3071

5. Manandhar B, Kim HJ, Rhyu DY. Caulerpa okamurae extract attenuates inflammatory interaction, regulates glucose metabolism and increases insulin sensitivity in 3T3-L1 adipocytes and RAW264.7 macrophages. J Integr Med. (2020) 18:253-64. doi: 10.1016/j.joim.2020.02.001

6. Zhou W, Teklu M, Bui V, Manyak GA, Kapoor P, Dey AK, et al. The relationship between systemic inflammation and increased left ventricular mass is partly mediated by noncalcified coronary artery disease burden in psoriasis. Am J Prev Cardiol. (2021) 7:100211. doi: 10.1016/j.ajpc.2021.100211

7. Mankhong S, Iawsipo P, Srisook E, Srisook K. 4-methoxycinnamyl p-coumarate isolated from Etlingera pavieana rhizomes inhibits inflammatory response via suppression of NF- $\mathrm{B}$, Akt and AP-1 signaling in LPS-stimulated RAW 264.7 macrophages. Phytomedicine. (2019) 54:89-97. doi: 10.1016/j.phymed.2018.09.193

8. Bao L, Dou G, Tian R, Lv Y, Ding F, Liu S, et al. Engineered neutrophil apoptotic bodies ameliorate myocardial infarction by promoting macrophage efferocytosis and inflammation resolution. Bioactive Mater. (2021) 9:18397. doi: $10.1016 /$ j.bioactmat.2021.08.008

9. Nakai K. Multiple roles of macrophage in skin. J Dermatol Sci. (2021) 104:210. doi: 10.1016/j.jdermsci.2021.08.008

10. Song Y, Huang Y, Zhou F, Ding J, Zhou W. Macrophage-targeted nanomedicine for chronic diseases immunotherapy. Chinese Chem Lett. (2021). doi: 10.1016/j.cclet.2021.08.090

11. Wang PY, Li J, Fatma AK, Kang WY, Wei JF, Liu ZH, et al. A critical review on chemical constituents and pharmacological effects of Lilium. Food Sci Hum Wellness. (2019) 8:330-6. doi: 10.1016/j.fshw.2019.09.001

12. Fortier AH, Falk LA. Isolation of murine macrophages. Curr Protoc Immunol. (2001). doi: 10.1002/0471142735.im1401s11

13. Zhan R, Xia L, Shao JH, Wang C, Chen DF. Polysaccharide isolated from Chinese jujube fruit (Zizyphus jujuba cv. Junzao) exerts antiinflammatory effects through MAPK signaling. J Funct Foods. (2018) 40:46170. doi: 10.1016/j.jff.2017.11.026

14. Emam SH, Sonousi A, Osman EO, Hwang D, Kim G, Hassan RA. Design and synthesis of methoxyphenyl- and coumarin-based chalcone derivatives as anti-inflammatory agents by inhibition of NO production and down-regulation of NF- $\mathrm{KB}$ in LPS-induced RAW264.7 macrophage cells. Bioorg Chem. (2021) 107:104630. doi: 10.1016/j.bioorg.2021. 104630

15. Verlan NV. To the question of safety of non-steroid anti-inflammatory drugs. Zhurnal Nevrologii I Psikhiatrii Imeni S S Korsakova. (2012) 112:96-8.

16. Tamura T. Practical guide and side effects of steroid anti-inflammatory drugs. Nihon Shika Ishikai zasshi. (1970) 23:165-8.

17. Mukta G, Singh N, Gulati M, Gupta R, Sudhakar K, Kapoor B. Herbal bioactives in treatment of inflammation: an overview. South Afr J Bot. (2021) 143:205-25. doi: 10.1016/j.sajb.2021.07.027

18. Bai R, Yao C, Zhong Z, Ge J, Xie Y. Discovery of natural antiinflammatory alkaloids: potential leads for the drug discovery for the treatment of inflammation. Eur J Med Chem. (2021) 213:113165. doi: 10.1016/j.ejmech.2021.113165

19. Asif H, Alamgeer, Ahmad MI, Alotaibi NH, Locatelli M. Phytochemical analysis and reappraisal of diuretic activity of Delphinium brunonianum Royle and its mode of action in experimental rats. Pak J Pharm Sci. (2020) 33:1833-8. doi: 10.36721/PJPS.2020.33.4.SUP.1833-1838.1

20. Yang XH, Jia ZP, Mao X, Zhang RX, Chong LI. Studies on the chemical constituents of Delphinium grandiflorum. J Chinese Med Mater. (2019) 42:1806-9.

21. Yan L, Wang F. Structure elucidation of diterpenoid alkaloids from Delphinium campylocentrum. Chinese J Org Chem. (2007) 27:976-80. doi: 10.1016/j.bmcl.2007.03.088

22. Liang S, Wei D, Wei S. Three new C19-diterpenoid alkaloids, delbrunine, delbruline and delbrusine from Delphinium brunonianum Royle. Heterocycles. (1986) 24:873. doi: 10.3987/R-1986-04-0873
23. Siebert M, Sommer S, Li SM, Wang ZX, Severin K, Heide L. Genetic engineering of plant secondary metabolism. Accumulation of 4hydroxybenzoate glucosides as a result of the expression of the bacterial ubiC gene in tobacco. Plant Physiol. (1996) 112:811-9. doi: 10.1104/pp.112.2.811

24. $\mathrm{Wu} \mathrm{XM}, \mathrm{Tu} \mathrm{PF}$. Isolation and characterization of alpha-(1->6)glucans from Cistanche deserticola. J Asian Nat Prod Res. (2005) 7:823-8. doi: 10.1080/10286020410001721087

25. Chen D. Study on chemical constituents of large polar parts of Desmodium caudatum. China J Chinese Mater Med. (2014) 39:3112-6. doi: $10.4268 / \mathrm{cjcmm} 20141621$

26. Desai HK, Pelletier SW. 13C-nmr Assignments for lactonetype norditerpenoid alkaloids. J Nat Prod. (1993) 56:21937. doi: $10.1021 / \mathrm{np} 50102 \mathrm{a} 027$

27. Pi J, Li T, Liu J, Su X, Wang R, Yang F, et al. Detection of lipopolysaccharide induced inflammatory responses in RAW264.7 macrophages using atomic force microscope. Micron. (2014) 65:1-9. doi: 10.1016/j.micron.2014.03.012

28. Wang HL, Xu XQ, Yin ZH, Wang MK, Wang BG, Ma CY. Activation of RAW264.7 cells by PCp-I, a polysaccharide from Psoralea corylifolia L, through NF-кB/MAPK signalling pathway. Int J Immunopathol Pharmacol. (2021) 35:1-12. doi: 10.1177/20587384211010058

29. Zhang, H.l, Guo Q, Liang ZH, Wang MK, Wang BG, et al. Anti-inflammatory and antioxidant effects of Chaetoglobosin Vb in LPS-induced RAW264.7 cells: Achieved via the MAPK and NF-кB signaling pathways. Food Chem Toxicol. (2020) 147:111915. doi: 10.1016/j.fct.2020.111915

30. Yang Y, Wei Z, Teichmann AT, Wieland FH, Wang A, Lei X, et al. Development of a novel nitric oxide (NO) production inhibitor with potential therapeutic effect on chronic inflammation. Eur J Med Chem. (2020) 193:112216. doi: 10.1016/j.ejmech.2020.112216

31. Schwarz L. Regulation of the expression of inducible nitric oxide synthase. Eur J Pharmacol. (2004) 500:255-66. doi: 10.1016/j.ejphar.2004.07.030

32. Salvador AF, Lima K, Kipnis J. Neuromodulation by the immune system: a focus on cytokines. Nat Rev Immunol. (2021) 8:526-41. doi: 10.1038/s41577-021-00508-Z

33. Imanishi J. Antitumor cytokines. Nihon rinsho. Jpn J Clin Med. (1992) 50:1737-41.

34. Chen X, Zhu X, Gong Y, Yuan G, Liu J. Porous selenium nanozymes targeted scavenging ROS synchronize therapy local inflammation and sepsis injury. Appl Mater Today. (2021) 22:100929. doi: 10.1016/j.apmt.2020.100929

35. Zinatizadeh MR, Schock B, Chalbatani GM, Zarandi PK, Jalali SA, Rouhollahmiri S. The Nuclear Factor KappaB(NF-kB) signaling in cancer development and immune diseases. Genes Dis. (2021) 8:11. doi: $10.1016 /$ j.gendis.2020.06.005

36. Bentley ER, Little SR. Local delivery strategies to restore immune homeostasis in the context of inflammation. Adv Drug Delivery Rev. (2021) 178:113971. doi: 10.1016/j.addr.2021.113971

37. Huang XY, Shao ZX, An LJ, Xue JJ, Li DH, Li ZL, et al. New lignanamides and alkaloids from Chelidonium majus and their anti-inflammation activity. Fitoterapia. (2019) 139:104359. doi: 10.1016/j.fitote.2019.104359

38. Xie Q, Wu GZ, Yang N, Shen YH, Tang J, Zhang WD. Delavatine $A$, an unusual isoquinoline alkaloid exerts anti-inflammation on LPSinduced proinflammatory cytokines production by suppressing NF-кB activation in BV-2 microglia. Biochem Biophys Res Commun. (2018) 502:2028. doi: 10.1016/j.bbrc.2018.05.144

39. Zhao L, Wang L, Di S, Xu Q, Ren Q, Chen S, et al. Steroidal alkaloid solanine A from Solanum nigrum Linn. exhibits anti-inflammatory activity in lipopolysaccharide/interferon $\gamma$-activated murine macrophages and animal models of inflammation. Biomed Pharmacother. (2018) 105:60615. doi: 10.1016/j.biopha.2018.06.019

40. Si Y, Li X, Guo T, Wei W, Zhang J, Jia A, et al. Isolation and characterization of phellodendronoside A, a new isoquinoline alkaloid glycoside with antiinflammatory activity from Phellodendron chinense Schneid. Fitoterapia. (2021) 154:105021. doi: 10.1016/j.fitote.2021.105021

41. Shibata T, Nagata K, Kobayashi Y. The mechanism underlying the appearance of late apoptotic neutrophils and subsequent TNF- $\alpha$ production at a late stage during Staphylococcus aureus bioparticle-induced peritoneal inflammation in inducible NO synthase-deficient mice. Biochim Biophys Acta. (2010) 1802:1105-11. doi: 10.1016/j.bbadis.2010.07.021 
42. Bignold R, Johnson JR. Effects of cytokine signaling inhibition on inflammation-driven tissue remodeling. Curr Res Pharmacol Drug Discov. (2021) 2:100023. doi: 10.1016/j.crphar.2021.100023

43. Pawlak M, Ho AW, Kuchroo VK. Cytokines and transcription factors in the differentiation of CD4+ $\mathrm{T}$ helper cell subsets and induction of tissue inflammation and autoimmunity. Curr Opin Immunol. (2020) 67:5767. doi: 10.1016/j.coi.2020.09.001

44. Guo Y, Li Q, Xuan YT, Wu WJ, Tan W, Slezak J, et al. Exercise-induced late preconditioning in mice is triggered by eNOS-dependent generation of nitric oxide and activation of PKC $\varepsilon$ and is mediated by increased iNOS activity. Int J Cardiol. (2021) 340:68-78. doi: 10.1016/j.ijcard.2021.08.021

45. Polese B, Thurairajah B, Zhang H, Soo CL, McMahon CA, Fontes G, et al. Prostaglandin E2 amplifies IL-17 production by $\gamma \delta \mathrm{T}$ cells during barrier inflammation. Cell Rep. (2021) 36:109456. doi: 10.1016/j.celrep.2021.109456

46. Aoki T, Narumiya S. Prostaglandins and chronic inflammation. Trends Pharmacol Sci. (2012) 33:304-11. doi: 10.1016/j.tips.2012.02.004

47. Chambers JM, Addiego A, Flores-Mireles AL, Wingert RA. Ppargcla controls ciliated cell development by regulating prostaglandin biosynthesis. Cell Rep. (2020) 33:108370. doi: 10.1016/j.celrep.2020.108370

48. Laudanno OM, Cesolari JA, Esnarriaga J, Flaherty P, Bedini OA. In vivo selectivity of anti-inflammatory drugs on COX2COX1 and gastrointestinal ulcers in rats. Gastroenterology. (1998) 28:249-55. doi: 10.1016/S0016-5085(98)80800-7

49. Jancinova V, Drabikova K, Killinger Z, Pazourekova S, Nosal R, Payer J. Novel aspects of the activation of NADPH oxidase in neutrophils of rheumatic patients on biological therapy. Int Immunopharmacol. (2019) 69:368-72. doi: 10.1016/j.intimp.2019.02.015

50. Xing YF, He D, Wang Y, Zeng W, Zhang C, Lu Y, et al. Chemical constituents, biological functions and pharmacological effects for comprehensive utilization of Eucommia ulmoides Oliver. Food Sci Hum Wellness. (2019) 8:177-88. doi: 10.1016/j.fshw.2019.03.013

51. Ahmed AF, Shi MJ, Liu,CY, Kang WY. Comparative analysis of antioxidant activities of essential oils and extracts of fennel (Foeniculum vulgare Mill.) seeds from Egypt and China. Food Sci Hum Wellness. (2019) 8:6772. doi: 10.1016/j.fshw.2019.03.004

52. Kanso F, Khalil A, Noureddine H, El-Makhour Y. Therapeutic perspective of thiosemicarbazones derivatives in inflammatory pathologies: a summary of in vitro/in vivo studies. Int Immunopharmacol. (2021) 96:10777892. doi: 10.1016/j.intimp.2021.107778

Conflict of Interest: The authors declare that the research was conducted in the absence of any commercial or financial relationships that could be construed as a potential conflict of interest.

Publisher's Note: All claims expressed in this article are solely those of the authors and do not necessarily represent those of their affiliated organizations, or those of the publisher, the editors and the reviewers. Any product that may be evaluated in this article, or claim that may be made by its manufacturer, is not guaranteed or endorsed by the publisher.

Copyright (C) 2022 Tang, Chen, Rizvi, Qu, Wang, Wang, Ma, Liu and Kang. This is an open-access article distributed under the terms of the Creative Commons Attribution License (CC BY). The use, distribution or reproduction in other forums is permitted, provided the original author(s) and the copyright owner(s) are credited and that the original publication in this journal is cited, in accordance with accepted academic practice. No use, distribution or reproduction is permitted which does not comply with these terms. 